\section{INTRODUCTION TO GEOLOGY}

\section{Geology for Everyman}

By the late Sir Albert Charles Seward. Pp. xi $+312+8$ plates. (Cambridge : At the University Press, 1943.) 10s. $6 d$. net.

$\mathrm{B}$ OTANIST, geologist and lover of Nature and of his fellow-men, Sir Albert Seward finished writing this book three days before his sudden death. It was evidently a labour of love-this endeavour to transmit to others his enthusiasm for the only real open-air science. Not only is the book an appeal to folk to take up geology as a hobby, but also it sets out "to present a case for the inclusion of an intelligent interest in" the subject "as part of that intellectual equipment we call culture, culture that has been defined as what remains after we have forgotten all we learnt at school". His descriptions "are not intended to serve as an elementary text-book"; his "hope is that they may be used as stepping stones to something higher and more scientific".

Such a book has long been needed, for geology has receded from the position it held a century ago as part of the natural equipment of an educated person. To-day its principles are little understood, and its discoveries and their implications are ignored. Perhaps people are put off by the scientific jargon which prevails in geology to an undue degree; but Seward's book proceeds in the first few chapters with many delightful personal touches to arouse an interest in the basic principles of the science with a minimal use of technical terms, though he pleads that "some of the technical terms in common use by geologists should find a place in the vocabulary of all educated people". It is perhaps questionable whether the bare minimum of principles given here will by itself provide a complete novice with sufficient knowledge to take the fullest advantage of the main part of the book which follows. This is devoted to the record that the rocks provide of an ever-changing geography brought about through the slow grinding away of land, and the growth of deltas, plains and mountains through the ceaseless movement of the crust and the equally inexorable changes of climate. Throughout, Seward uses the changing geographical scene as the background to organic evolution.

It is natural that the author of "Plant Life throughout the Ages" and of the standard text on "Fossil Plants" makes evolution one of the main themes of his book, with particular emphasis on the changes in plant life from age to age. As this is an aspect of the stratigraphical record to which Seward had devoted his life, and one that rarely receives adequate recognition in geological text-books, the treatment is rightly developed on a fuller and more satisfying scale than that accorded to the animals, though their palæontological record is not neglected. General readers for whom the book is intended will be attracted to the study of fossils through the clear way in which their significance is brought out.

The method adopted in this book of treating the geological periods from the newest to the oldest has the sanction of authority in that it was used by Lyell; but it inevitably leads to repetitions, some of which are irritating and tend to distract from the sequence of the events. But in this book each chapter is an exposition of one or two major principles or important incidents rather than a description of an ordered cavalcade of events. Doubtless Seward intended to excite interest in some particular part of the geological record and to show what sort of things can be deduced from it, and for this purpose was not over-concerned with its dating. Here are some of his themes: Britain under the arctic conditions of the Ice Age, post-Glacial climatic changes and their effects on the vegetation, de Geer's system of geochronology, the changing floras of the Tertiary and their interpretation in terms of climate, the building of the Alpine chain, the break in mid-Cretaceous times between ancient and modern types of plants, the salt lakes and deserts of the New Red Sandstone, the origin of coal, the value of careful fossil collecting and the contribution to science that it can make even in the hands of amateurs.

The chapters relating to the Cretaceous, Tertiary and Glacial periods are very interesting and attractively written, and so are the ones on fossils ("Medals of Creation") and on the "Procession of Life" ; but strangely enough the one on the origin of coal is disappointing and surprisingly misleading over the composition of that much-analysed substance. Naturally the older formations are more difficult to deal with; but a sense of their influence on scenery, their antiquity and of the strangeness of the forms of life that they contain, is vividly conveyed. "The world, to our limited vision, appears to be almost static ; mountains we have thought of as symbols of eternity, seen through geological spectacles, take their place as episodes in a series of events which have moulded the changing features of the earth's face. The rocky covering of the world viewed by geologists, 'foreshortened in the tract of time', reveals itself as a dynamic mobile crust responding from age to age to constructive and destructive forces which have operated since the earth's early youth."

This is a book so full of wisdom, wit and learning that it cannot fail to convey to its readers the author's lifelong enthusiasm. For this reason alone it is particularly welcome to-day, for it will take an honoured place among the instruments designed for that wider education of young people and adults which we all look forward to after the War. It will find its most appropriate niche in the school library and on the bookshelves of students' hostels, clubs and unions; but it should also make a strong appeal to lovers of the country and to the not inconsiderable number of persons who like 'to go geologizing'.

L. J. WruLs.

\section{PLANT GEOGRAPHY OF THE MEDITERRANEAN REGION}

\section{Das Pflanzenkleid der Mittelmeerländer}

Von Prof. Dr. M. Rikli. Lieferung 3. Pp. 241-352+ 13 plates. Lieferung 4. Pp. 353-436+14 plates. (Bern : Hans Huber, 1943.) 9 Schw. francs each.

7 HE publication of another two serial parts of Dr. Rikli's book on the plant cover of the Mediterranean region completes volume 1 of this work (for an account of the first two parts see NATURE, $152,117 ; 1943)$. Part 4 includes the title-page and list of contents of the volume, together with a short preface by the author. In the latter it is noted that the large number of maps showing the geographic distribution of numerous different species in the region have been prepared on the basis of the classical floristic works and partly in consultation with specialists on certain parts of the Mediterranean basin. The advantage of these maps is the rapidity with 